\title{
Self-Esteem and Adjustment to Retirement Among Retiree Teachers in Meru County, Kenya
}

\author{
Aileen Gacheri Akwalu Mugambi ${ }^{1} \quad$ Beatrice Mwarania Mburugu ${ }^{2}$ John Kamoyo Mwithalii ${ }^{2}$ \\ 1Department of Social Sciences, Chuka University \\ 2.Department of Education, Chuka University
}

\begin{abstract}
Retirement poses psychological problem for many retirees. There is an increase in the number of retired teachers in Meru County in Kenya because majority of the pioneer teachers in Meru County have begun retiring since independence. It was necessary to establish the relationship between self-esteem and adjustment to retirement. The researcher established a relationship between self-esteem and adjustment to retirement among retiree teachers in Meru County. The study adopted descriptive survey research design. The study sampled 318 respondents from a population of 1800 comprising of 600 retirees, 600 spouses of retirees and 600 close relatives of the retiree teachers. A sample of 318 respondents was selected to participate in the study. Data was collected from retiree teachers and their spouses through questionnaires. Interview schedules were used to collect data from retiree teacher close relative. Quantitative data was analyzed with the help of Statistical Package for Social Science (SPSS) version 23. Descriptive statistics included frequencies, percentages, standard deviation and mean. Inferential statistics used was wilcoxon signed rank test. Qualitative data collected was analyzed by classifying the responses into meaningful categories thematically. The findings of this study revealed that there is a significant relationship selfesteem and adjustment to retirement. The study recommends that Teacher Service Commission to organize preretirement training and counseling to prepare teachers to handle challenges that may affect their self-esteem in retirement.
\end{abstract}

DOI: $10.7176 / \mathrm{JRDM} / 68-05$

Publication date:August $31^{\text {st }} 2020$

\section{Introduction}

Retirement is gradually becoming a topic of research in contemporary society. This is because it is one of the challenges associated with aging. Growing old is not easy and involves life changes which demand multiple adjustments requiring stamina, ability and flexibility. The loss of work through retirement is one of the major adjustments for aging individual (Eliopoulos, 2010). Retirement therefore, it is a major stage in adult development and it essentially marks the split from middle years to old age. By the time one gets to retirement mental and physical exuberance has dwindled thus it becomes rational to relieve the person of some strenuous and excruciating duties that may weigh them down and consequently threaten their health.

Retirement can mean different things to different people. For some, retirement may mean reducing the amount of work hours per week from full-time to part time status, while for others it may mean working on a voluntary basis (Marshall, 2004). To others it can mean partial or complete withdrawal from career work accompanied by change in the source and decrease in income. According to Peeters, Van, Anne, Goldberg, Shore and Lipka, (2008) retirement is a complex social phenomenon that signifies the detachment from customary activities in business, industry, or active services as full-time employee. Hartman (2014) asserts that retirement is important because it reduces the stress level of employees and gives retirees the time to rest, exercise and lead a healthier life in general. The assertion is supported by (Marshall, 2004) who states that retirees have ample time to interact with family members, friends and engage in community activities. Contrary to assertions by Hartman (2014) and Marshall (2004), Drummond (2003) asserts that retirement affects income and employment status leading to reduced selfesteem among some retirees.

According to Longino (2009), retirees go through six phases. The first phase is the pre-retirement phase when the employee is preparing to retire. Then there is the actual retirement date when the employees leave the organization and get farewell messages or even a farewell party. After the farewell, the next phase is the honeymoon phase where the retiree feels that they are now free to do all that they dreamt of doing during their working period. Once the honeymoon phase is over the retiree now faces the reality of retirement at the disenchantment phase. If the disenchantment phase is not properly managed retirees develop Psychological problems one of them being complications with self-esteem (Longino, 2009). Many people who have been looking forward to retirement for a long time, when many retirees reach this phase they must deal with the feelings of being let down. They realize that retirement is not a permanent vocation after all, and that retirement brings along the feelings of loneliness, boredom, feelings of uselessness and disillusionment.

The mandatory retirement age varies from country to country, and even within the same country it may still vary based on occupation and gender (Kwesi\& Allen, 2012), generally ranging between 55-75 years (Kim, Kwon $\&$ Anderson, 2005). The standard age of retirement in Kenya is 60 years with some exceptions where some 
employees retire at the age of 65 and 75 such as members of judiciary, university staff and researchers at the research centers (Ross \& Willis, 2009). Many retirees in Kenya face a lot of challenges in securing their pension and other benefits hence hitting on their self-esteem negatively. The teachers' in Kenya retire at the age of sixty years. However, teachers with disabilities and registered by the National Council for Persons with Disabilities have their retirement age set as sixty five years according to government of Kenya policy (GoK, 2012).

Ogunbameru (2004) reported that retirement is a major crisis especially in sub-Saharan Africa. The transition from work to retirement is often perceived as resulting into loss of status especially leading to esteem problems and other psychological problems. The views by Ogunbameru (2004) were corroborated by the findings of Anyah (2008) who stated that teachers in Ghana feared to and were refusing to go on retirement because of boredom and loss of sense of self-worth which is attributed to lack of pre- retirement counseling.

Self-esteem refers to how a person feels about them self. It is how people view themselves positively or negatively. It can also refer to the overall attitude towards oneself. Individuals with high self-esteem respect view themselves as useful individuals. Self-esteem is affected by three qualities of the worker's job: autonomy, power, and opportunities for socialization (Neff, 2009). Some of the factors that have been found to impact self-esteem are: education, income, and heath and employment status especially as people aged. People who have higher incomes and better health in later life tend to maintain their self-esteem as they age. This could be associated to the fact that it is possible that wealth and health are related to feeling more independent and better able to contribute to one's family and society which in turn boosts self-esteem.

Self-esteem was also found to be positively associated with financial satisfaction, optimism about the financial future, and future expectations of improvement in their financial situation Hira and Mugenda (1998). All these factors are often affected by retirement. High self-esteem is considered important because it is associated with higher levels of psychological health and functioning, and low levels of self-esteem are undesirable because it is associated with lower levels of psychological health and functioning (Glaus, 1999). A strong sense of selfesteem is needed among elderly population to whom every day is a struggle. The elderly population is suffering from decreased mobility, disabilities, and failing health can certainly affect one's sense of self-esteem.

Many people invest a lot in their time in careers and neglect other areas of their lives. These people suddenly feel emptiness and despair when they retire. People whose sense of self-esteem and worth is dependent on the work they do are particularly at risk of developing low self-esteem after retirement Peeters, Van, Anne, Goldberg, Shore and Lipka, (2008). They may feel that they have lost their purpose for living, that they are worthless and do not have a role to play in the society.

Research findings have shown that self-esteem takes a bit of a dive around the age of retirement. Midlife is a period mostly associated with highly stable work, family and solid romantic relationships. Things change when one enters retirement. It is a period that can mean that one is too old for many employers despite having the skills and experience they required and that can make somebody's health start to suffer as a result. It is easy to think of retirement as the end of somebody's value. Retirees could have become so caught up in their work, identity or their worth as a parent that the idea of losing those identities can fill them with dread (Drummond 2003). These studies on self-esteem did not establish the relationship between self-esteem and retiree teacher adjustment to retirement hence the study found it necessary to establish how teacher retirees adjusting to challenges of selfesteem in retirement.

\section{Statement of the problem}

Retirement is viewed with great anticipation and anxiety, probably because of the uncertainties regarding the future. It is a threat to many workers who may not know what to do with their lives after retiring from active service. This poses psychosocial problems such as low self-esteem to many retirees. These problems are described as having relationships with many life circumstances such as finances, bridgework, family issues, housing issues, and physical health, pension among others during retirement. Previous studies have found a link between self-esteem and adjustment to retirement. However, these studies were mainly focused in the developed countries whose setups may not be the same as the developing countries in general and Kenya in particular hence this study intends to fill the gap.

\section{Objective of the Study}

The study set out to establish the relationship between self-esteem and adjustment to retirement among retiree teachers in Meru County of Kenya

\section{Hypothesis}

$\mathrm{H}_{01} \quad$ There is no statistically significant relationship between self-esteem and adjustment to retirement among retiree teachers in Meru County, Kenya. 


\section{Research Design}

This study adopted a descriptive survey research design.

\section{Location of the Study}

The study was conducted in Meru County. Meru County is the home of the Ameru. There are ten sub-counties in Meru County namely, Igembe North, Igembe Central, Igembe South, Tigania East, Tigania Central, Tigania West, Buuri, Imenti North, Imenti Central and Imenti South. Meru shares its border with five counties: Isiolo to the North, Nyeri to the South West, Laikipia to the West, Mwingi to the East and Tharaka Nithi to the South East.

\section{Population of the Study}

The study targeted 600 teachers from Meru County who had retired from the Teachers Service Commission between 2014 and 2018 (TSC, 2018). Spouses and selected close relatives of the retiree teacher participated in the study. Therefore the target population comprises of 600 retiree teachers, 600 spouses to retiree teachers and 600 close relatives of retiree teachers hence a population of 1800 persons.

\section{Sampling Procedures and Sample Size}

A sample of 318 respondents who were proportionately selected was used in this study. The sample was distributed as shown it Table 1:

Table 1: Sample Size

\begin{tabular}{lccc}
\hline Group & Population & Sample Size & Sampling Procedure \\
\hline Retiree Teacher & 600 & 106 & Snowballing \\
Spouses of Retiree Teachers & 600 & 106 & Purposive \\
Retiree Teachers 'close relatives & 600 & 106 & Simple Random \\
Total & 1800 & 318 & \\
\hline
\end{tabular}

\section{Research Instruments}

Questionnaires and interview schedules were used to collect data from the respondents.

\section{Questionnaire}

Two sets of structured questionnaire were used to collect data. A set of questionnaires were made for the retired teachers and another set for the spouses of retiree teachers.

\section{Interview Schedule}

Interview schedule was used to collect qualitative data from the close relatives of retiree teachers.

\section{Data Analysis}

Quantitative data was analyzed with the help of Statistical Package for Social Science version 23 using descriptive and inferential statistics. Descriptive statistics included frequencies, percentages, standard deviations and means. Inferential statistics used were one sample Wilcoxon signed rank test. The variables used were the 10-item Kessler psychological distress scale (K10) scores obtained from the retirees' data (Bougie et al., 2016). The Kessler psychological distress scale $(\mathrm{K} 10)$ is designed to measure anxiety and depression through a10-item questionnaire. Each question pertains to an emotional state and each has a five-level response scale. The higher the score, the greater the psychological distress due to depression or anxiety. A score of less than 15 shows no distress or anxiety. A score of 16-30 indicates moderate distress and a score of over 30 means high distress (Blanc et al., 2014)

\section{Ethical Considerations}

The researcher appreciated human dignity by ensuring privacy and respecting the autonomy. All information collected was treated with utmost confidentiality. The researcher also explained all that entails the research. Potential respondents were given information about the study objectives to ensure they are well explained. Consent from the respondent was sought and anonymity was guaranteed. Citations and acknowledgement was included for previous work cited in the research proposal so as to avoid plagiarism. Informed consent was sought from the respondents who had expressed the need of counseling services and they were given a form to sign. The researcher endeavored to have truthful representation of the data collected from the respondents.

\section{Demographic Characteristics for Retirees}

The demographic characteristics for the retiree teacher's that were considered in this study were; the spouses' gender, marital status and religion. Among the respondents, 50\% were male and 50\% were female. Most of the retired teachers were aged $61-65$ years). The recommended age of retirement for teachers in Kenya is 60 years. Over $50 \%$ of the retired teachers in this study were 60 years and above. However, there were still retired teachers 
who aged less than 60 years. These are the teachers who could have retired through early retirement. According to information on the teacher service commission's website, a teacher may apply to retire on attainment of 50 years and on completion of 10 years' continuous service on permanent and pensionable terms. Such a teacher shall apply in writing through the head of institution giving three months' notice, stating the intended date of retirement. Upon receipt of the application, the commission considers the application and issues a retirement notice. The commission then processes retirement claim upon receipt of required documents from the teacher. The claim is then forwarded to the director of pension, treasury, for payment (Code of Regulations for Teachers, 2015).

Analysis of the retired teachers by religion and marital status showed that the highest percentages of the retired teachers in Meru count were Christians and they were married |. The retired teachers who had retired as primary school teachers were $40.57 \%$ while $33.02 \%$ were secondary school teachers

\section{Demographic Characteristics of the Retiree Teachers Spouses}

The demographic characteristics for the retiree teacher's spouses that were considered in this study were; the spouses' gender, marital status and religion. $53.8 \%$ of the retirees' spouses who were respondents in this study female and $46.2 \%$ of the spouses were males. Analysis of the ages of the spouses to the retiree's s teachers indicated that $13.21 \%$ were below 50 years, 19.81\% were between 51-55 years while $33.96 \%$ were between $56-60$ years. The results showed that majority of the spouses had attained the retirement age just as the retirees. Analysis of the retiree teacher's spouses who based on their religion showed that $8.49 \%$ of the spouses did not belong to any religion. Majority of the spouses (53.77\%) were Christians with the next highest percentage being the Muslims. The Hindus, African traditional believers and other religions accounted for about $10 \%$ of the respondents in this study who were spouses to the retirees.

\section{Demographic Characteristics of the Retiree Teacher's close Relatives}

The demographic characteristics of the retiree's close relatives that were considered to be in this study were the relative's gender, age and duration of the relationship between the retirees and the relative. Results indicate that $51.9 \%$ of relatives who were respondents in this study were males while $48.1 \%$ of the relatives were females. The average age of the relatives to retiree teachers was 45.46 years.

\section{Self-Esteem and Adjustment to Retirement}

The descriptive statistics analysis results were obtained by summarizing the responses of the retirees, the retirees' spouses and relatives. The results on self-esteem and adjustment to retirement were based on the responses from teacher retirees, spouses of teacher retirees and close relatives of the teacher retirees.

\section{Retirees' Responses on Self-esteem and Adjustment to Retirement}

Descriptive statistics were used to analyze retirees' responses to a questionnaire self-esteem and adjustment to retirement: Table 2.

Table 2: Retirees' Responses on Self-esteem and Adjustment to Retirement

\begin{tabular}{|c|c|c|c|c|c|c|c|c|c|c|}
\hline Variable & 5 & 4 & 3 & 2 & 1 & f & Med. & Avg & sd. & mode \\
\hline I have hard time nurturing myself & 47 & 17 & 8 & 6 & 28 & 106 & 4 & 3.49 & 1.68 & 5 \\
\hline I turn down invitations to parties because I fear about myself since retirement & 46 & 22 & 11 & 4 & 23 & 106 & 4 & 3.63 & 1.57 & 5 \\
\hline I support others but belittle myself since retirement & 33 & 30 & 13 & 9 & 21 & 106 & 4 & 3.42 & 1.5 & 5 \\
\hline I blame myself whenever things go wrong since retirement & 39 & 24 & 9 & 9 & 25 & 106 & 4 & 3.41 & 1.61 & 5 \\
\hline I begin each day with a negative attitude since retirement & 41 & 27 & 9 & 7 & 22 & 106 & 4 & 3.55 & 1.56 & 5 \\
\hline I feel undeserving since retirement & 36 & 32 & 8 & 5 & 25 & 106 & 4 & 3.46 & 1.57 & 5 \\
\hline I feel like an imposter and soon my deficiencies will be exposed & 44 & 23 & 13 & 6 & 20 & 106 & 4 & 3.61 & 1.53 & 5 \\
\hline I have an inner critic who is demeaning me since retirement & 31 & 33 & 11 & 10 & 21 & 106 & 4 & 3.43 & 1.48 & 4 \\
\hline I believe that being hard on myself is the best motivation for change since retirement & 43 & 29 & 8 & 10 & 16 & 106 & 4 & 3.69 & 1.46 & 5 \\
\hline I feel unattractive since retirement & 27 & 34 & 18 & 6 & 21 & 106 & 4 & 3.38 & 1.44 & 4 \\
\hline My good points seem ordinary and my failings all important since retirement & 48 & 20 & 11 & 9 & 18 & 106 & 4 & 3.67 & 1.53 & 5 \\
\hline I feel unappreciated since retirement & 34 & 29 & 14 & 7 & 22 & 106 & 4 & 3.43 & 1.51 & 5 \\
\hline I feel lonely since retirement & 39 & 30 & 8 & 8 & 21 & 106 & 4 & 3.55 & 1.53 & 5 \\
\hline I criticize myself often after retirement & 32 & 37 & 7 & 5 & 25 & 106 & 4 & 3.43 & 1.54 & 4 \\
\hline Others criticize me since retirement & 41 & 24 & 14 & 5 & 22 & 106 & 4 & 3.56 & 1.53 & 5 \\
\hline I struggle with feelings of inferiority since retirement & 33 & 32 & 11 & 4 & 26 & 106 & 4 & 3.4 & 1.56 & 5 \\
\hline I hesitate to do things because of what others might think since retirement & 48 & 23 & 7 & 7 & 21 & 106 & 4 & 3.66 & 1.57 & 5 \\
\hline
\end{tabular}

Likert scale score strongly agree $=5$, agree $=4$, not sure $=3$, disagree $=2$, strongly disagree $=1$

The retirees tended to agree that they had hard time nurturing themselves, they had turned down invitations to parties because they feared about themselves since retirement, supported others but belated themselves since they retired, blamed themselves whenever things went wrong since retirement, they begun each day with a negative attitude since retirement, felt like an imposter and felt that soon their deficiencies would be exposed and they had an inner critic who was demeaning them. They also agreed that they believed that being hard on themselves was the best motivation for change, they felt unattractive, their good points seemed ordinary and their failings were all important, they felt lonely, they criticized myself often, others criticized them, struggled with feelings of inferiority, 
hesitated to do things because of what others might think

\section{Retirees' Spouses Responses on Self-esteem and Adjustment to Retirement}

Descriptive statistics was used to analysis the responses of retiree's spouses on self-esteem and retirement based:

Table 3

Table 3: Responses of Retirees' Spouses' on Self-esteem and Adjustment to Retirement

\begin{tabular}{|c|c|c|c|c|c|c|c|c|c|c|}
\hline Variable & 5 & 4 & 3 & 2 & 1 & Freq & med & Avg & $\mathrm{Sd}$ & mode \\
\hline $\begin{array}{l}\text { Your spouse have hard time nurturing } \\
\text { themselves since retirement }\end{array}$ & 19 & 25 & 29 & 2 & 31 & 106 & 3 & 2.99 & 1.47 & 1 \\
\hline $\begin{array}{l}\text { Your spouse has ever turned down } \\
\text { invitations to parties because he/she } \\
\text { fears about him/herself since } \\
\text { retirement }\end{array}$ & 16 & 23 & 49 & 8 & 10 & 106 & 3 & 3.25 & 1.1 & 3 \\
\hline $\begin{array}{l}\text { Your spouse is supportive of others } \\
\text { but belated him/herself since } \\
\text { retirement }\end{array}$ & 42 & 42 & 4 & 4 & 14 & 106 & 4 & 3.89 & 1.33 & 4 \\
\hline $\begin{array}{l}\text { Your spouse blames him } / \text { herself } \\
\text { whenever things go wrong since } \\
\text { retirement }\end{array}$ & 14 & 31 & 26 & $\begin{array}{l}1 \\
0\end{array}$ & 25 & 106 & 3 & 3.01 & 1.36 & 4 \\
\hline $\begin{array}{l}\text { Your spouse begins each day with a } \\
\text { negative attitude since retirement }\end{array}$ & 38 & 24 & 26 & 7 & 11 & 106 & 4 & 3.67 & 1.31 & 5 \\
\hline $\begin{array}{l}\text { Your spouse feels undeserving since } \\
\text { retirement }\end{array}$ & 31 & 26 & 31 & 9 & 9 & 106 & 4 & 3.58 & 1.23 & 5 \\
\hline $\begin{array}{l}\text { Your spouse feels like an imposter and } \\
\text { soon his/her deficiencies will be } \\
\text { exposed }\end{array}$ & 40 & 44 & 5 & 4 & 13 & 106 & 4 & 3.89 & 1.3 & 4 \\
\hline $\begin{array}{l}\text { Your spouse has an inner critic who is } \\
\text { demeaning him/her since retirement }\end{array}$ & 24 & 41 & 26 & 4 & 11 & 106 & 4 & 3.59 & 1.19 & 4 \\
\hline $\begin{array}{l}\text { Your spouse believes that being hard } \\
\text { on myself is the best motivation for } \\
\text { change since retirement }\end{array}$ & 39 & 48 & 4 & 4 & 11 & 106 & 4 & 3.94 & 1.23 & 4 \\
\hline $\begin{array}{l}\text { Your spouse feels unattractive since } \\
\text { retirement }\end{array}$ & 22 & 39 & 30 & 5 & 10 & 106 & 4 & 3.55 & 1.16 & 4 \\
\hline $\begin{array}{l}\text { Your spouse good points seem } \\
\text { ordinary and his/her failings all } \\
\text { important since retirement }\end{array}$ & 40 & 39 & 12 & 4 & 11 & 106 & 4 & 3.88 & 1.26 & 5 \\
\hline $\begin{array}{l}\text { Your spouse feels unappreciated since } \\
\text { retirement }\end{array}$ & 19 & 43 & 31 & 5 & 8 & 106 & 4 & 3.57 & 1.08 & 4 \\
\hline $\begin{array}{l}\text { Your spouse feels lonely since } \\
\text { retirement }\end{array}$ & 18 & 41 & 13 & $\begin{array}{l}2 \\
4\end{array}$ & 10 & 106 & 4 & 3.31 & 1.26 & 4 \\
\hline
\end{tabular}

Likert scale score strongly agree $=5$, agree $=4$, not sure $=3$, disagree $=2$, strongly disagree $=1$

The retirees spouses agreed that the retirees were supportive of others but belated themselves since retirement, begun each day with a negative attitude since retirement, felt undeserving since retirement, felt like an imposter and soon their deficiencies would be exposed, had an inner critic who was demeaning them since retirement, believed that being hard on themselves was the best motivation for change since retirement, felt unattractive since retirement, their good points seemed ordinary and their failings were all important since retirement and felt unappreciated since retirement |Table 11|. However, they were not sure if the retirees had hard time nurturing themselves since retirement, had ever turned down invitations to parties because they fear about themselves since retirement and blamed themselves whenever things went wrong since retirement.

\section{Retirees' Close Relatives Responses on Self-esteem and Adjustment to Retirement}

Close relatives to the retirees were interviewed on self-esteem and adjustment to retirement: Findings revealed that relatives $(35.85 \%)$ had observed that the retirees experienced reduced self-confidence and reduced self-respect among the retirees. Emptiness and despair among the retirees was also observed by $28.3 \%$ of the relatives. These results shows that retirement had negatively affected the retirees 'self-esteem.

Relationship between Self-Esteem and Adjustment to Retirement

Relationship between self-esteem and adjustment retirement was investigated inferentially using the Wilcoxon signed rank test using the K10 scores for the self-esteem. The K10 scores for self-esteem obtained were graphically 
presented in a histogram: The histogram was skewed to the right. This means that the scores were not normally distributed. This justified the use of the Wilcoxon signed rank test which is non-parametric and does not require the scores to be normally distributed.

The hypothesis tested using the obtained K10 scores was;

$H_{0}: M=40$ Self-esteem did not change after retirement

$H_{1}: M>40$ Self-esteem changed after retirement

The result of showed that the computed value of the Wilcoxon signed rank test statistic was 4675.5 with a probability value of $3.90 \mathrm{E}-12$. The probability value for the test statistic was less than the level of significance (5\%).The hypothesis stated that there is no significant relationship between self-esteem and adjustment to retirement among retiree teachers in Meru County Kenya. This means that the null hypothesis that self-esteem did not change after retirement was rejected when at $5 \%$ level of significance. This showed that there was a statistical significant relationship between self-esteem and adjustment to retirement among retired teachers.

Different perspectives have characterized retirement either in terms of losses or in terms of potential gains, and the pathways through which such losses and gains may impact retirees' psychological well-being and selfconcept remain largely unclear. These perspectives argue can lead to psychological stress and potentially also to decreases in retirees' self-esteem, particularly for those who view their career as central to their identity. The results of this study are similar to ones from a study that revealed that retirees experienced a change in self-esteem trajectory following retirement (Bleidorn, \&Schwaba, 2018). This was attributed to a reason that people who have invested a lot in their careers and neglected other areas of their lives suddenly feel emptiness and despair when they retire. People whose sense of self-esteem and worth is dependent on the work they do are particularly at risk. They may feel that they have lost their purpose for living, that they are worthless and do not have a role to play in the society. After looking forward to retirement for a long time, when many retirees reach this phase they must deal with the feelings of being let down. They realize that retirement is not a permanent vocation after all and that retirement brings along the feelings of loneliness, boredom, feelings of uselessness and disillusionment. Others can sink into depression and appear more likely to deepen their depression as time in retirement increases. Aging also tends to affect identity and self-confidence in terms of what activities are possible. Another similar study on life without professional work-perceptions about one's self, interpersonal relations and social life after retirement, found out that retirement had a significant impact on their perceptions of their life situation. Concerns resulting from retirement were further described as a sense of the declining status in society (Dahlheim-Englund et al., 2019).

Studies reviewed have obtained similar results to the ones in this study. They have found out that some of the factors that impact on self-esteem is; Education, income, health and employment status especially as people aged. People who have higher incomes and better health in later life tend to maintain their self-esteem as they age. This could be associated to the fact that it is possible that wealth and health are related to feeling more independent and better able to contribute to one's family and society, which in turn bolsters self-esteem. Retirement affects income and employment status leading to reduced self-esteem. Research findings also in agreement to this study have also shown that self-esteem takes a bit of a dive around the age of retirement (Drummond, 2003). Midlife is a period mostly associated with highly stable work, family and solid romantic relationships. Things change when one enters retirement. It is a period that can mean that somebody is too old for many employers despite having the skills and experience they required, and that can make somebody's health starts to suffer as a result. It can be easy to think of retirement as the end of somebody's value. Retirees could have become so caught up in their work identity or their worth as a parent that the idea of losing those identities can fill them with dread.

\section{Conclusion}

The study set out to establish if there was a statistical significant relationship between self-esteem and adjustment to retirement among retiree teachers in Meru County. This was inferentially tested using the Wicoxon signed rank test. These results led to rejection of the null hypothesis. It was thus concluded that adjustment to retirement affected the self-esteem of the retired teachers. This was also evident from the analysis of the responses of the retirees, their spouses and their close relatives.

\section{Recommendations}

The study recommend that it is necessary for The Teachers Service Commission to organize pre-retirement counseling and preparedness training among teachers who are near retirement in Meru County to minimize the effects of retirement on their self-esteem. .

\section{References}

Eliopoulos, C. (2010). Gerontological Nursing (7th ed.). Philadelphia: Lippincott Williams \& Wilkins Company. Hira, T, \& Mugenda, O, (1998). Predictors of Financial Satisfaction: Differences Between Retirees And Nonretirees.

Financial 
https://www.researchgate.net/publication/228594269

Longino, C.F. (2009). Retirement. Encyclopedia of Life Course and Human Development 328 - 334. Available online at http://www/emeraldinsight.com /doi/abs/10/1108/0950412101102670.

Marshall, G.L. (2004). The Golden years African American Women and Retirement.Retrieved 09/12/2008 from the World Wide Web http://www.rcgd.isr.umich. edclu/prba/pespectivesummary2004/mcshall.pdf.

Ogunbameru, O. (2004).Attitudes towards Retirement and Pre-retirement Education among Nigerian Bank Workers in Educational Gerontology 30 (5) 391-401.

Openda, J. (2018). Retired Teachers Tell Misery in Battle for Sh. 52bn Pension. Daily Nation: $6^{\text {th }}$ October, 2018.

Peeters, M., Van Ememerik, H., Anne, T.M., Goldberg, C., Shore,L.M., \& Lipka, P. (2008).The Effects of Retirement Expectations and Social Support on Post-retirement Adjustment.A Longtudinal Analysis. Journal of Management Psychology.23 458-470. 10. 1108/02683940810869051. 